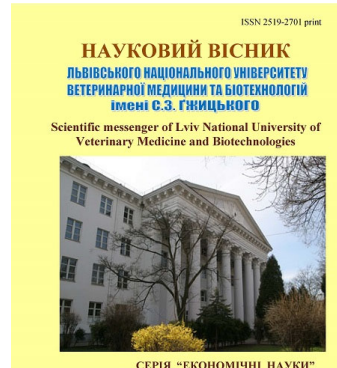 \\ СЕРЯЯ "ЕКОНОМІЧН НАУКИ \\ Том 22 № 96 2020 Науковий вісник Дьвівського націонадьного університету
ветеринарної медицини та біотехнологій імені С.З. Гжицького. Серія: Економічні науки

\author{
Scientific Messenger of Lviv National University \\ of Veterinary Medicine and Biotechnologies. \\ Series: Economical Sciences
}

UDC 658:004.7

\section{Digitalization in Ukraine's economy in the context of world digitization}

\author{
M. Dorosh-Kizym ${ }^{1}$, O. Dadak ${ }^{1}$, M. Dorosh ${ }^{2}$, L. Babych $^{1}$ \\ ${ }^{1}$ Stepan Gzhytskyi National University of Veterinary Medicine and Biotechnologies Lviv, Lviv, Ukraine \\ ${ }^{2}$ Lviv University of Business and Law, Lviv, Ukraine
}

Article info

Received 11.11.2020

Received in revised form 14.12 .2020

Accepted 15.12.2020

Stepan Gzhytskyi National University of Veterinary Medicine and Biotechnologies Lviv, Pekarska Str., 50, Lviv, 79010, Ukraine. Tel.: +38-063-814-56-55 E-mail:mim.dorosh@gmail.com

Lviv University of Business and Law, Kulparkivska Str., 99, Lviv, 79021, Ukraine.

\begin{abstract}
Dorosh-Kizym, M., Dadak, O., Dorosh, M., \& Babych, L. (2020). Digitalization in Ukraine's economy in the context of world digitization. Scientific Messenger of Lviv National University of Veterinary Medicine and Biotechnologies. Series: Economical Sciences, 22(96), 9-14. doi: $10.32718 /$ nvlvet-e 9602
\end{abstract}

The world has entered the era of the fourth industrial revolution - a period in which digitalization plays perhaps the most significant role for production, and innovative technologies such as virtual reality, internet of things, artificial intelligence and robotics are fundamentally changing the way people work and the way they live. The backbone of modern society is a rapidly growing network of electronic knowledge and tools that includes manufacturers, suppliers, sellers, buyers and users of information in electronic form. The information sphere of the state directs its economic and innovative potential, and thus significantly affects other spheres, such as competitiveness in the international arena and the quality of citizens' life. Today Ukraine is at a unique stage of development when there is a chance to make the so-called "digital leap" in key spheres of the economy. That is, to quickly move to a new stage of development in these spheres, bypassing intermediate stages, and starting to use modern systems at once, bypassing several generations of technologies. The percent of the digital economy in Ukraine is gradually steadily increasing, but the pace of its development is still low. In order to keep up with the world's leading economies forever, it is necessary to begin large-scale digitization of all industries as soon as possible, investing as much as possible in the development of digital infrastructures, innovations and modern technologies. Moreover, the country has potential, especially in the IT sphere, where Ukraine's position is quite good. Technologically, Ukraine is still in the last century because the state has very low domestic demand for technology. The actual tasks for Ukraine in this sphere, on the one hand, are the implementation of its own digital potential, and on the other, the implementation of relevant EU documents and projects into national legislation. In addition, it is important to develop the spheres of science and education, without which it is impossible to count on progress in the development of the information society and the knowledge economy. Every year, technologies go forward, new trends are gaining momentum, affecting all the schemes by which people do business in the digital world. And in order to stay ahead of the competition or even just to "stay in the game", you need to learn to work with new tools, track trends and be flexible enough to adapt to these changes.

Key words: digitalization, digitization, industrial revolution, virtual reality, creative culture, online business, blockchain technologies, freelancers, downshifters, interactive marketing, millennials, omnichannel, digital marketing, ambient media, connectors, cybersecurity, soft skills, sharing economy, Internet of things, Bitcoin cryptocurrency, crowdsourcing, digitally transformed, IT market, digitally-born, Industry4.0.

\section{Introduction}

Information is a key resource in the modern world. Every second, humanity generates huge amounts of digital data that not only require storage space, but also help companies do business. To take advantage of all the possibilities of the available information, it is necessary to accumulate, structure and analyze it.
The development of the digital economy of Ukraine consists in the creation of market incentives, motivations, demand and the formation of needs for the use of digital technologies, products and services among Ukrainian sectors of industry, spheres of life, business and society for their efficiency, competitiveness and national development, growth in the production of high-tech products and well-being of the population. 
Digitalization has spawned its own economy - a system that has become an indispensable attribute of our reality as well as its authorities (leading countries), who recognized trends in time and managed to be on the crest of its wave. This global trend led to changes in the way of production in almost all industries that were in its appearance, and it still does.

Global digitalization provides for the implementation of measures to introduce appropriate incentives for the digitization of the economy, public and social spheres, awareness of the existing challenges and tools for the development of digital infrastructures, the acquisition of digital competencies by citizens, and also identifies critical spheres and projects of digitization, stimulating the internal market, use and consumption of digital technologies.

The path to the digital economy lies through the internal market for the production, use and consumption of information, communication and digital technologies.

Sectors of the economy using digital technologies are growing faster, cheaper and better. The spheres of life, including education, medicine, transport, are being modernized thanks to digital technologies, becoming much more efficient and creating exceptionally new value and quality.

Analysis of recent research and publications. The relevance of this research is reflected in numerous scientific works of Ukrainian and foreign scientists. The theoretical principles and practical aspects of the application of digitalization were considered in the works of Tepskot D., Borden N., Calliton D., Vishnevsky V. (Vishnevsky et al., 2020), Boyko L. (Boyko et al., 2019), Boronos V. (Boronos et al., 2018), Kloba L. (Kloba, 2018), Rudenko M. (Rudenko, 2018), Yanovska V. (Yanovska et al., 2019), Hrybinenko O., Dyba M., Herneha Y., Korol S., Fedulova L., Lazebnyk L., and the like.

The formulation of the goals of the article is to study the appropriateness of the implementation and use of digitalization and digitization tools, highlighting their advantages and disadvantages compared to traditional classical methods of doing business.

\section{Material and methods of research}

In the process of research of digitalization of economic processes in Ukraine the following methods were used: for processing the volume of statistical and empirical data - economic-statistical methods; for in-depth study of individual elements of the studied phenomenon - monographic methods; to illustrate certain researched phenomena, processes and regularities - graphic methods; for a detailed study of the studied phenomenon by analyzing its structure, individual features, properties, relationships methods of analysis and synthesis and comparisons; to study the experience of the researched problems in different countries of the world and to establish separate positive elements in the given research - a method of methodological and historical approach in economic researches. The method of observation was used to reveal some features of the behavior of producers and consumers of digitalized products.

\section{Results and discussion}

Digital transformation is a natural process of social and business development. This evolutionary stage is special - it removes barriers and globalizes the market. Now we communicate, learn and compete not with each other, but with other countries, markets, communities. Success or failure in this so-called race will divide the world into two classes: countries - aware leaders who create future-defining values and innovation; and societies - ordinary consumers who are trailing "in the tail" of civilization.

At the beginning of the last century, British economist John Keynes determined that demand stimulates supply. However, for the Ukrainian reality, this is not always the case, and especially when it comes to high-tech IT products. The domestic business market, most likely, follows the principles of the "Say's Law" according to which the proposal forms the need for a certain product or service. Actually, this is the situation in which an enterprise can work for years using outdated methods and the dominance of human labor at every stage. And as soon as technologies appear from a competitor, become a condition of a loan or an international grant, the enterprise is "forced" to become innovative.

The creation of demand and the formation of needs provides for the implementation of a targeted and innovative policy of creating in various spheres of life such conditions (technological environment, digital infrastructures) that would induce citizens and business, instead of the usual analogue (traditional) means and tools, to use digital as more efficient, faster, cheaper and better quality.

In the age of information technology, the transition to a digital economy is inevitable. After all, those who quickly realize the main trends in the development of the world community will receive more benefits. The digital economy is a type of economy where the key factors (means) of production are digital data: numerical, textual, and the like. Their use as a resource can significantly increase the efficiency, productivity, value of services and goods and build a digital society. A digital society is a society that intensively and productively uses digital technologies for its own needs (self-realization, work, rest, education, leisure of everyone), as well as for achieving and realizing joint economic, public and social goals.

The digital economy covers business in all sectors of economic activity, that is, not only in the information and telecommunications sector, but also in basic industries, agriculture, construction, and the like. The digital economy permeates all sectors across all categories: public and private; real, non-productive and financial, extractive, manufacturing and service sectors.

Digital technologies are both a huge market and industry, as well as a platform for the efficiency and competitiveness of all other markets and industries. High-tech production and modernization of industry through information and communication and digital technologies, the scale and pace of digital transformations should be a priority of economic development.

The dictionary of modern Ukrainian language and slang "Myslovo" chose "digitalization" as the word of the year 2019. And, in general, given how many times this 
neologism has appeared in official press materials, it is difficult to disagree with this choice of an online dictionary (Digitalization, 2019).

The term of digitalization by a wide margin topped the list of the most visited words of the dictionary, and the number of views increased by $1.535 \%$ compared to the previous year. The neologism, which entered the Ukrainian language only a few years ago, is a transliteration of English digitalization and, according to the definition of the dictionary, means changes in all spheres of public life associated with the use of digital technologies. The word is a simplified form of the more accurate term "digital transformation" and is a manifestation of the global digital revolution.

Digitalization is an opportunity to develop a business using new technologies, create new products and improve customer experience, as well as improve internal business processes, and work on the expenditure side. Digital tools can be applied to almost any field. Moreover, digitalization is a call of the times. Companies that have embraced technology earlier than others have a competitive advantage. There are companies that were born in the digital era, the so-called "digitally-born". And there are those who lived in the analog process but saw the opportunities that new technologies provide, and consciously came to use these tools - digitally transformed.

The digital economy means a new level of digital services when almost all operations go online. And for industrial enterprises, the transition into the digital economy has been defined in the world as Industry 4.0 - the fourth industrial revolution. The term "fourth industrial revolution" is a logical continuation of the concepts of the first, second and third industrial revolutions. The first industrial revolution began in the second half of the XVIII century after the advent of steam engines that made it possible to move from manual labor to a machine, and, the use of energy from coal and the industrial printing house acted as the main communication tool.

The second revolution was characterized by the development of mass conveyor production, oil energy and the emergence of the internal combustion engine, electrification, the emergence of telephone networks, radio and television as the main communication tools.

The third industrial revolution, also called the digital revolution, began in the second half of the XX century with the creation of digital computers and the further evolution of information technology. Our world lives in this era. The digital revolution in this period of time turns into the fourth, a feature of which is the massive introduction of cyber-physical systems into production. The term "fourth industrial revolution" originated from the famous Swiss economist Klaus Martin Schwab after its publication in the Foreign Affairs magazine (also called the modern "capitalist manifesto"). He suggests calling the fourth industrial revolution digital, since its special characteristic is the blurring of the distinction between the physical, digital and biological spheres.

The first steps of the world towards a new industrial revolution were cloud technologies, the development of methods for collecting and analyzing Big Data, crowdsourcing, biotechnology, self-driving cars and medicine based on 3D printing. In the world of finance, these are Bitcoin cryptocurrency and Blockchain technologies. Although the third industrial revolution in the world is not over yet, the developed countries of the world have already entered the fourth phase of the global economy with one foot.

One of the key features of the fourth industrial revolution is uncertainty. Industry 4.0 is just beginning to gain momentum, therefore it is still impossible to fully predict its impact on the future of mankind. According to the representatives of the World Economic Forum, currently 25 countries are ready for a successful entry into the new era - these are the countries that already account for $75 \%$ of the value added of global industrial production. Most of them are EU countries, as well as countries in East Asia and North America.

The list of the most innovative companies in the world is topped by Apple, Google, Tesla and Microsoft. And the most innovative countries include, in addition to the United States, Switzerland, Germany, Japan, Sweden, the Netherlands, and South Korea.

In this report, Ukraine is included in the "Eurasia" category and along with Argentina and Indonesia is listed in the list of "immature" countries. There is a certain danger in it because technological progress is moving too fast, and, having caught the right pace at the initial stages, it will be much more difficult to catch up with it.

Undoubtedly, the driver, the reason for Industry 4.0 was the leap in the development of information technology, but the main process is Digitalization, digitization, and digitalization of the industry.

Industry 4.0 is a digital transformation of production processes (digitization in enterprises) (Fig. 1).

The main elements of the fourth industrial revolution will be continuous innovations that will completely change the way of life of people as well as affect consciousness (that is, gradually change the very nature of man). Many markets will work directly, bypassing various intermediary structures: brokers and dealers.

Digital transformation is the introduction of modern technologies into the business processes of an enterprise. This approach involves not only the installation of modern equipment or software, but also fundamental changes in approaches to management, corporate culture, and external communications. As a result, the productivity of each employee and the level of customer satisfaction are increased, and the company gains a reputation for being a progressive and modern organization. Digitization is a recognized driver of economic growth due to the ability of technology to positively influence the efficiency, effectiveness, cost and quality of economic, social and personal activities. Digitization requires new forms of partnership and cooperation in various spheres of the economy and society, guided by certain principles (Fig. 2). Digitization is the saturation of the physical world with electronic digital devices, means, systems and the establishment of electronic communication interaction between them. 


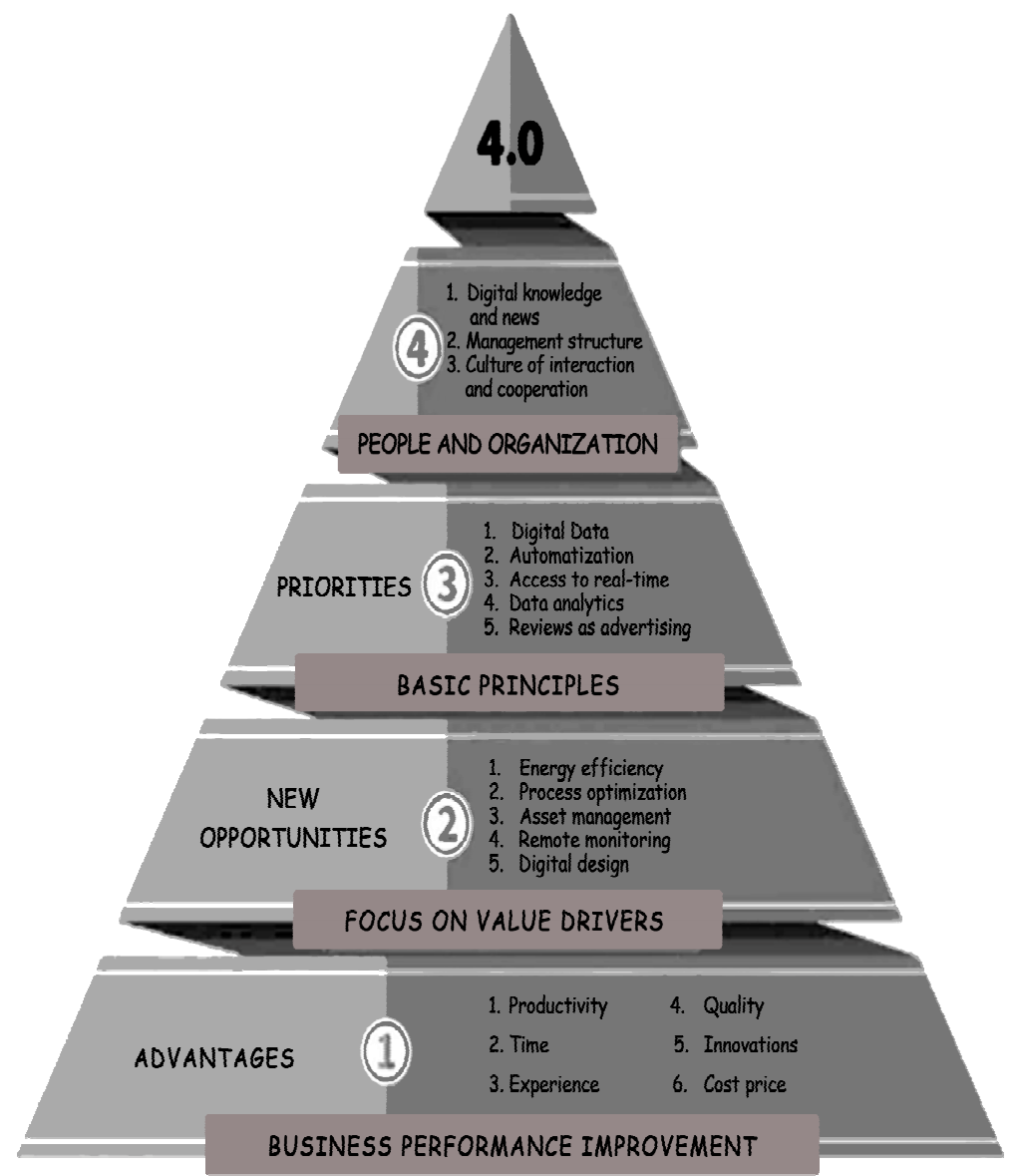

Fig. 1. Classification of needs for transition to Industry 4.0

Source: based on https://strategy.uifuture.org/kraina-z-rozvinutoyu-cifrovoyu-ekonomikoyu.html

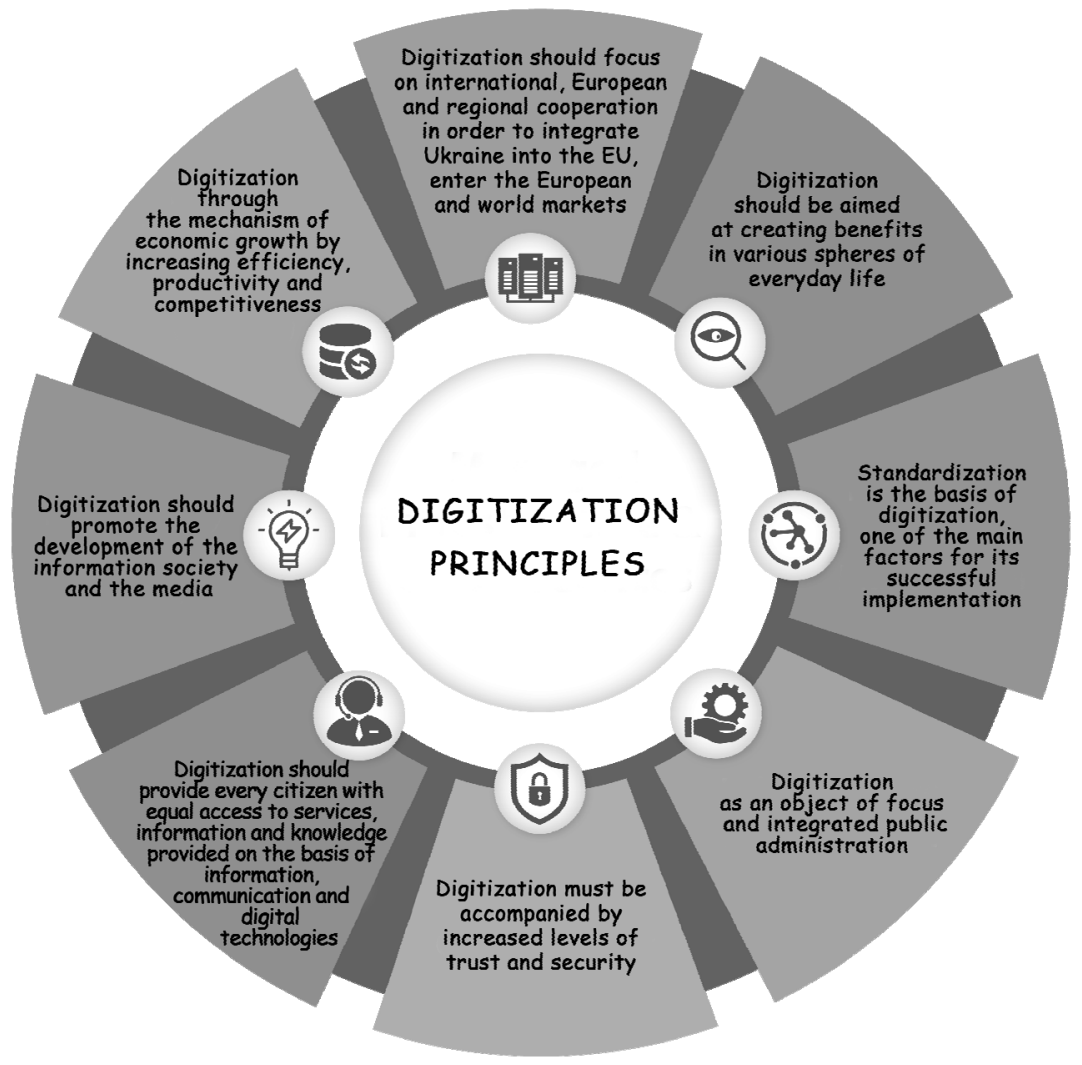

Fig. 2. Main digitization principles

Source: based on https://strategy.uifuture.org/kraina-z-rozvinutoyu-cifrovoyu-ekonomikoyu.html 
Digitization should be seen as a tool, not an end in itself. With a systematic state approach, digital technologies stimulate job creation, increase productivity, economic growth and the quality of life of Ukrainian citizens.

Opportunities that the digitization trend creates for Ukraine:

- competitive growth of the economy sectors;

- development of the digital economy and labor market;

- emergence of new industries;

- development of innovative entrepreneurship.

At one time, D. Kennedy was the first to draw attention to the fact that the Chinese hieroglyph, which means the concept of "crisis", is translated in two ways - as "danger" and "opportunity". True, some linguists only partially agree with this interpretation, since "opportunity" is not the main meaning of one of the hieroglyphs. But we propose to consider the crisis as an opportunity. Any crisis destroys old methods, plans, concepts and forms new models for effective communication and cooperation skills.

The labor market around the world is showing a geometric progression in the number of freelancers, downshifters and remote employees. This makes it possible for the businesses to save, in particular, on rent, equipment, furniture, stationery and more. The most popular "virtual vacancies" are now available for millennials, $\mathrm{Z}$ and $\mathrm{Y}$ generations. Usually, employees who want to work remotely are even willing to get less for work at home than for office work. Thus, remote work will become a new reality. The digital workplace is the virtual equivalent of a physical workplace, which requires proper organization, use and management, as it must be the key to increased employee productivity and a better working environment for them.

In the digital economy, jobs are no longer tied to physical places. They become "digital", virtual, mobile, that is, those that do not require the employee to stay at the workplace all the time. The concept of "digital workplaces" is spreading extremely quickly in the business environment and is perceived positively by the vast majority of workers who like flexible ways of working, the ability to work from home, on vacation, that is, from anywhere.

The digital workplace promotes flexibility in the methods of performing official duties by civil servants, stimulates their joint work and interaction, supports decentralized and mobile work environments, and provides a choice of technologies for work. The advantages of digital workplaces are the reduction of costs for hardware, office space, business trips, etc.

In addition, digitalization can lead to certain changes in the structure of agricultural production in Europe because new technologies increasingly make the management of farms larger, and small farms are often unable to implement some of the proposed technologies due to lack of resources.

In countries such as Argentina, Australia and Brazil, agriculture is actively being digitalized. Ukraine is also following this path, and the EU countries need to think about how to support the existing structure - to subsidize or look for other ways to be competitive in world markets.
On the other hand, it is necessary to understand that digitalization creates conditions for the sustainable development of small farms, because it can facilitate their access to sales markets, for example, using blockchain technologies, as well as reduce the bureaucratic burden and the associated costs of money and time in terms of reporting to the authorities, and in terms of gaining new knowledge, communication with suppliers, consultants, and the like.

The processes of digitalization are a modern driver of development not only of the economy and society, but also of the state, requiring a comprehensive implementation of digital transformations. Confirmation of this idea is the creation in September 2019 of the Ministry of Digital Transformation of Ukraine, as the main body in the system of central executive authorities, ensuring the formation and implementation of state policy in the field of digitization, digital development, digital economy, digital innovation, e-government and e-democracy, development of the information society, development of infrastructure for broadband Internet access and telecommunications networks, e-commerce and business. From the list of the main tasks of the new ministry, we highlight the areas of work related to the sphere of digitization of the economy, including agriculture.

\section{Conclusions}

Ukraine has all the conditions for the implementation of the so-called digital transition to a higher technological level of development, namely: ability to produce and use information and communication and digital technologies, and availability of professional staff. This is evidenced by the statistics of real successes of Ukrainian IT companies in international markets; access to appropriate equipment, technology, technology diffusion among citizens and businesses. This is evidenced by the gradual recovery of domestic demand for technology, market "success stories" in various spheres of life and economy, the presence of local representative offices of technology manufacturers, distribution of high-tech equipment; sufficient level of system integration of technological products and services - from design to complex implementations of various technologies, software and hardware; creative culture and ability to generate ideas, as evidenced by high performance in the Global Innovation Index. Digitization is the first step towards stimulating domestic consumption markets, the introduction and production of digital technologies. It contains the vision of transforming the economy from traditional to effective digital, determines the priority steps for the implementation of appropriate incentives and the creation of conditions for digitalization in the real sector of the economy.

Prospects for further research. In conclusion, it should be noted that modern business and enterprises of the traditional economy must technically and quickly adapt to change in order to be successful in the model of digital transformation, setting the task of becoming a digital leader. Despite the scale of scientific advances that are already available, it is still important in the future to conduct research aimed at developing tools and mechanisms for working in a virtual economic environment - 
because the business world is becoming faster, global, mobile and digital every day.

\section{References}

Boronos, V., Plikus, I., Aleksandrov, V., \& Antoniuk, N. (2018). Digital transformation of Ukraine: challenges of theory and practice in implementation of digital quality of life. Economic Annals-XXI, 172(7-8), 3843 doi: 10.21003/ea.V172-07.

Boyko, L., Bieliaieva, N., \& Bay, S. (2019). Digital Economy: Problems and Prospects of Development in Ukraine. International Journal of Recent Technology and Engineering (IJRTE), 8(3), 226-229. doi:10.35940/ijrte.C1038.1183C19.

Digitalization - the word of 2019 in Ukraine according to the online dictionary "Myslovo" https://itc.ua/news/didzhitalizacziya-slovo-2019-rokuv-ukrayini-za-versiyeyu-onlajn-slovnika-mislovo/ (in Ukrainian).
Kloba, L. H. (2018). Digitization is innovative to the development of banks. Efektyvna ekonomika, 12. doi: 10.32702/2307-2105-2018.12.84.

Rudenko, M. (2018). Digitalization of economy: new opportunities and perspectives. Ekonomika ta derzhava, 11, 61-65. doi: 10.32702/2306-6806.2018.11.61.

Vishnevsky, V., Harkushenko, O., Kniaziev, S., Lypnytskyi, D., \& Chekina, V. (2020). Digitalization of Ukrainian economy: transformational potential. Monograph ISBN: 978-966-360-398-8, PH “Akademperiodyka”, Kyiv. doi: 10.15407/akademperiodyka.398.188 (in Ukrainian).

Yanovska, V., Levchenko, O., Tvoronovych, V., \& Bozhok, A. (2019). Digital Transformation of the Ukrainian Economy: Digitization and Transformation of Business Models. SHS Web of Conferences, 2019, 67. doi: 10.1051/shsconf/20196705003. 